\title{
Coarse Particles Revisited
}

\author{
Alvaro Osornio Vargas \\ Department of Pediatrics, University of Alberta, Canada.
}

A recent publication on Sciences Advances entitled "Climate models miss most of the coarse dust in the atmosphere" (Adebiyi and Kok, 2020) caught my eye, mainly because of the relevance of the topic and my interest in dust from a toxicological perspective.

It was interesting to read the authors' claim that current climate models underestimate the participation of coarse dust (suspended particles with aerodynamic diameters $\geq 5 \mathrm{mu}$ ). It is an interesting claim, because coarse dust from deserts has a well established role in climate (Miller and Tegen 1997). Desert dust contributes particles that serve as effective nuclei for water droplets and ice crystals, impacting the amount and spatial distribution of clouds. They also absorb radiation affecting the atmospheres' stability and circulation. The authors argue that existing measurements of dust in the atmosphere support a more substantial presence than anticipated.

Compiling existing measured amounts of atmospheric dust, the authors developed new dust parameterizations for climate simulations. They found that coarse particles are four-times higher than previously considered. Their model indicated a substantial underestimation of the impacts of dust, namely, warming at the top of the atmosphere. A closer look at the potential reasons that led to an underestimate of the participation of coarse dust in previous models identified the use of a specific assumption in them. The assumption resides in the "roundedness" of the particles; previous models assumed that particles were closer to spheres than they are in reality.

Well supported assumptions are necessary for science. They are essential steppingstones in the process of moving forward. In that sense, we proceed by approximation as a result of the collective work of scientists around the world that continuously favors the update of the supporting assumptions used at a given time. Assumptions often serve to justify and frame the research question and, in some other instances, to account for the inclusion of specific variables in modelling exercises. 
The previous paragraph illustrates how the performance of a climate model can be improved when new evidence allows for the removal of a previously-used assumption. However, cross-checks are necessary. The peer-review process is one of them, but also sharing results in scientific meetings and lab seminars play essential roles. Critical thinking, scientific methodological rigour and open-mindedness are core elements involved in the process. Nevertheless, the increased focalization and sub-specialization of the research activities can bias our perspectives missing the opportunity of timely removal of outdated assumptions.

Now, let us now talk about my perspective on the assumptions used when studying the toxic effects of the particles that pollute the air in urban settings.

There is no doubt that urban air pollution is having a significant effect on human health around the world (World Health Organization, 2020). Evidence collected during the last 70 years in many cities of the world indicates that monitored pollutants associate with several health problems. One of the monitored pollutants that consistently explains the reported health effects is the mass concentration of the particles suspended in the air, known as particulate matter or PM.

The characterization of air quality commonly relies on the measurement of a handful of pollutants (ozone, nitrogen dioxide, sulphur dioxide, carbon monoxide and particulate matter). Since the strongest associations with health problems related to one of them (particulate matter or PM) (Loxham et al., 2019), we frequently work under the current assumption that particulate matter can solely explain the measured impacts of air pollution on health.

A second assumption relates to the size of the particulate matter. Particulate matter (PM) comes in different sizes (Figure 1), determining its potential to penetrate the body. The level of penetration could explain why the particle levels in the atmosphere associated with health problems that have an impact beyond the point of entry (the respiratory system) like, for example, in the cardiovascular system or an embryo. Air pollution and, specifically particulate matter, can trigger premature mortality, asthma attacks, heart attacks and arrhythmias, as well as, babies born too soon or too small and even cancer. Stronger associations occur when considering fine particles ( $\mathrm{PM}_{2.5}$ fraction) than those observed when studying coarser particles ( $\mathrm{PM}_{10}$ 
or those with an aerodynamic diameter of $\leq 10 \mathrm{mu}$ ).

Experimental research confirms that PM can induce many of the toxic effects documented at the epidemiological level, providing biological plausibility to the associations identified at the population level. As a result, new research builds on the robust assumptions that PM is the pollutant of interest and, more specifically, PM of smaller sizes.

Later last year, our colleagues from the Hong Kong Polytechnic University and Fudan University in China wrote a relevant commentary acknowledging that air pollution represents a global problem that requires local assessments of its impact (Li et al., 2019). This commentary makes sense since the sources of pollution vary from city to city. Therefore, it may be time to challenge the accepted assumption that small particulate matter equally impacts health.

It is time to study the participation of other coexisting contaminants, especially those of which we know little about because we do not monitor them regularly, or because they are not being monitored at all. Let me add another layer of complexity if we consider that the wealth of information about air pollution and health comes primarily from developed countries (see interesting map in Fajersztajn et al., 2013), where sources of particles favor a predominant $\mathrm{PM}_{2.5}$ fraction over the $\mathrm{PM}_{10}$ one. What about cities in developing countries where unpaved roads or erosion are still a primary source of soil particles in the air? A local example could be Mexicali, Baja California. Mexicali is one of the top Mexican cities with higher levels of $\mathrm{PM}_{10}$ in the country, resulting from human activities and erosion (dust storms) (INECC, 2017).

There are two other aspects worth keeping in mind about coarse particles. One is the dynamic changes in their chemical composition and increased toxicity when arriving and mixing with other pollutants in urban settings (Querol et al., 2019). And the other, the wealth of biologicals and microorganisms (e.g., pollen, bacteria, fungi) that are present and transported in this fraction (Naas et al., 2018; Zhai et al., 2018). These two aspects are still under active research, and we do not fully understand their impact on climate and health.

Interestingly, evidence exists indicating that particles induce differential 
cellular responses related to their size but also to their composition. Soil content in coarser particles drives different responses than organic-rich smaller particles (Manzano-Leon et al., 2016) (Figure 2). Also, introducing new methodological approaches to our research can help us understand complex interaction. Data mining allowed us to identify an increased risk for babies born too small or too soon when considering particles combined with various organic compounds in a region with high petrochemical activities (Serrano-Lomelin et al., 2019).

Maybe it is time to challenge the accepted assumptions that helped us focus our questions on the health impacts of air pollution and bring into the questions' context the local characteristics of the area of study.

Challenging existing assumptions should be the results of the scientific process. However, scientists' natural tendency to focus on narrower and narrower areas of specialization can blur our capacity to identify the need to adjust the existing assumptions. Exposure to other disciplines and research groups helps us review and reflect on the assumptions used in our research. Different perspectives are always useful. Students need specific training to understand the context of their research questions and the assumptions upon which they build their research. Our tendency to focus training on learning methodologies has removed the opportunity to engage in the conceptual training necessary to understand context and assumptions.

If we go back to the coarse particles, recent evidence suggests that we need to revisit their participation in air pollution and climate. I propose an approach working as interdisciplinary teams to create new assumptions and build a more holistic approach to understand the impact of human and natural activities on the environment and, consequently, on health. 


\section{ATMÓSFERA

Figures:

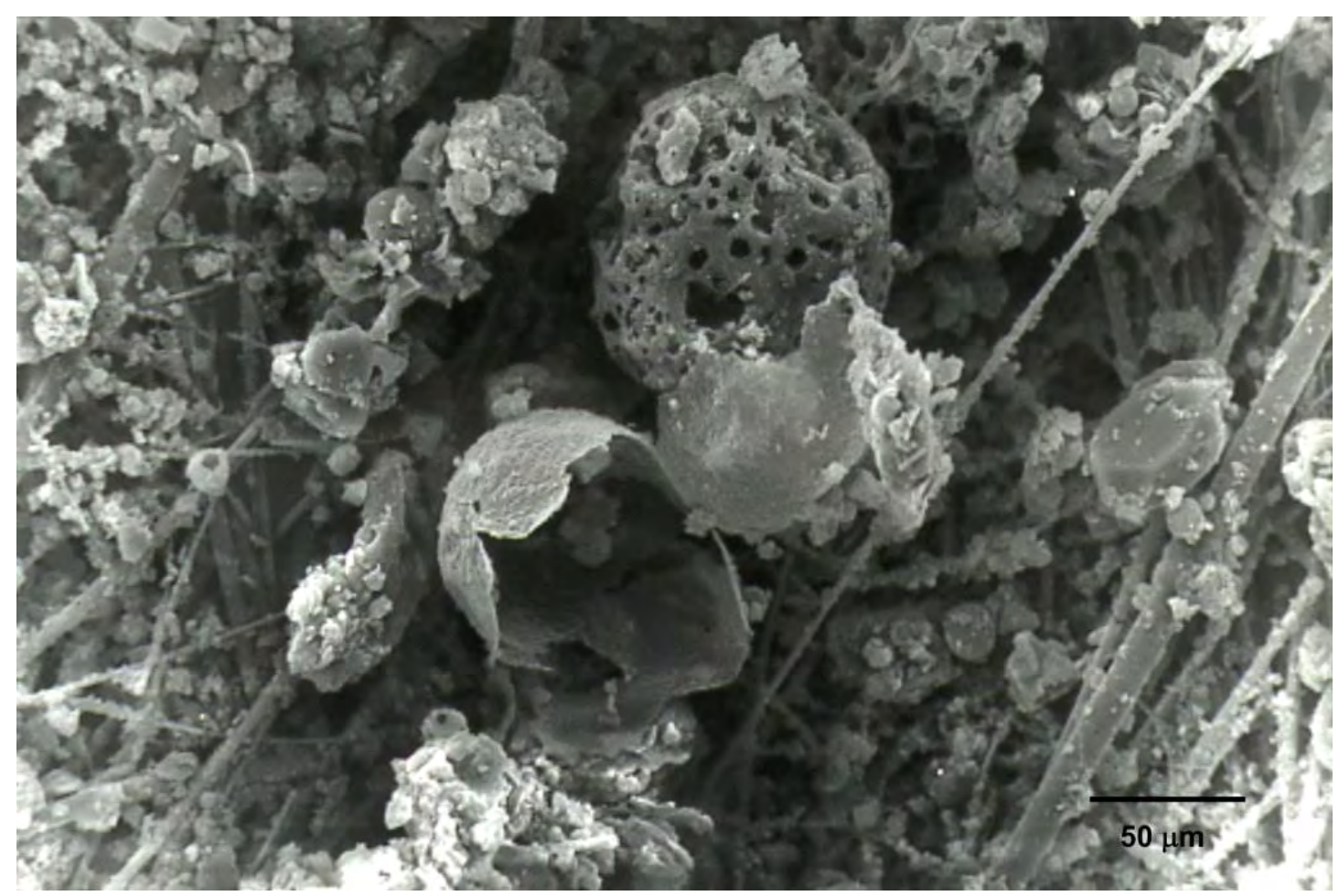

Figure 1. Scanning electron microscopy image of total suspended particles collected in Mexico City using a high vol sampler and fibreglass membranes. Note the particle heterogeneity in size and shape. 


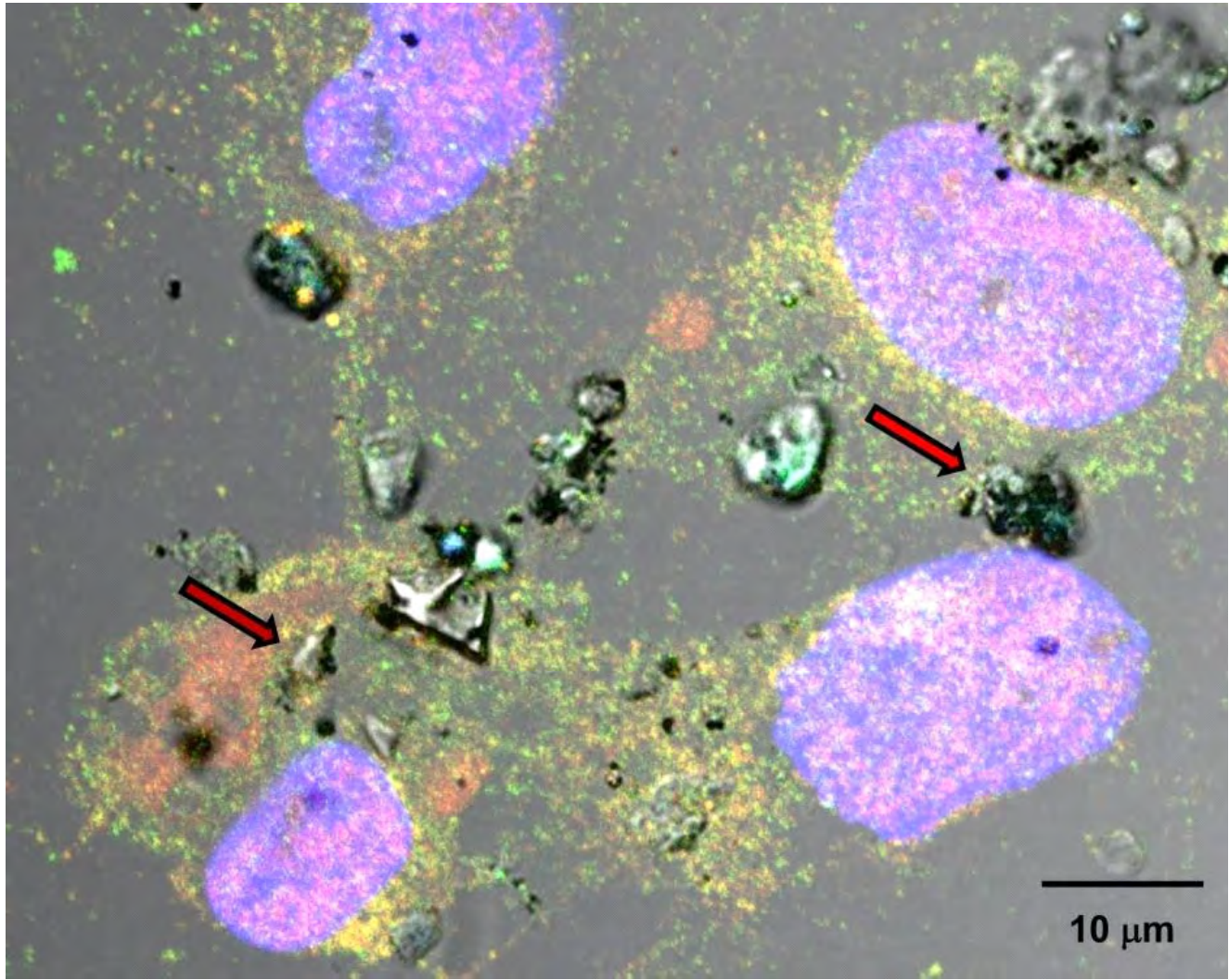

Figure 2. In vitro exposures to PM (arrows) from Mexico City induce cellular responses depending on their composition. For example, when the coarse particles are rich in organic compounds, they can cause the production of detoxifying enzymes (cytochrome P450) (see greenish granules in the cytoplasm). Cytochrome P450 production needs that the organic compounds in the particles bind to the aryl hydrocarbon receptor (AhR) in the cytoplasm (see red granules). Then, they reach the nuclei of the cells to induce its gene expression (see red granules in the purple nuclei). This phenomenon indicates that the particles are capable of influencing the cellular production of detoxifying enzymes, probably resulting from the organic content of the particles. $\mathrm{PM}_{10}$ from Mexico City has a higher content of organic compounds during the winter months.

Confocal microscopy, red granules represent the AhR and greenish ones, cytochrome P450. Cell nuclei are in purple. 
Figures:

Adebiyi, A.A., Kok, J.F. 2020. Climate models miss most of the coarse dust in the atmosphere. Science Advances 6(15): eaaz9507. doi: 10.1126/sciadv.aaz9507

Fajersztajn, L., Veras, M., Barrozo, L., Saldiva, P. 2013. Air pollution: a potentially modifiable risk factor for lung cancer. Nat Rev Cancer 13: 674-678. doi: 10.1038/nrc3572.

INECC. Informe Nacional de Calidad del Aire 2017, México. Coordinación General de Contaminación y Salud Ambiental, Dirección de Investigación de Calidad del Aire y Contaminantes Climáticos. Instituto Nacional de Ecología y Cambio Climático. Ciudad de México, 2018. Available online: https://www.gob.mx/inecc/prensa/inecc-pone-a-disposicion-el-informe-nacionalde-calidad-del-aire-2017?idiom=es (accessed on May 18, 2020)

Li, X., Jin, L., Kan, H. 2019. Air pollution: a global problem needs local fixes. Nature 570, 437-439. doi: 10.1038/d41586-019-01960-7

Loxham, M., Davies, D.E., Holgate, S.T. 2019. The health effects of fine particulate air pollution BMJ 367:16609. doi: 10.1136/bmj.16609.

Manzano-León, N., Serrano-Lomelín, J., Sánchez, B.N., Quintana-Belmares, R., Vega, E., Vázquez-López, I., Rojas-Bracho, L., López-Villegas, M.T., Vadillo-Ortega, F., De Vizcaya-Ruiz, A., Rosas Pérez, I., O’Neill, M.S., OsornioVargas, A.R. 2016. TNF $\alpha$ and IL-6 responses to particulate matter in vitro: Variation according to PM size, season, and polycyclic aromatic hydrocarbon and soil content. Env Health Perspect 124(4):406-412. Doi: 10.1289/ehp.1409287.

Miller R, Tegen I. 1997. Desert Dust, Dust Storms and Climate. National Aeronautics and Space Administration, Goddard Institute for Space Studies. 
https://www.giss.nasa.gov/research/briefs/miller_01/ (accessed May 18, 2020).

Naas, O., Mendez,M., Quijada, M., Gosselin, S., Farah, J., Choukri, A., Visez, N. 2016. Chemical modification of coating of Pinus halepensis pollen by ozone exposure. Environmental Pollution, 214:816-821, doi:10.1016/j.envpol.2016.04.076.

Osornio-Vargas AR, Serrano J, Rojas-Bracho L, Miranda L, Garcia-Cuellar C, Reyna MA, Flores G, Zuk M, Quintero M, Vazquez I, Sanchez-Perez Y, Lopez T, Rosas I. 2010. In vitro biological effects of airborne PM2.5 and PM10 from a semi-desert city on the México-US border, Chemosphere 83:618-626, doi.org/10.1016/j.chemosphere.2010.11.073.

Querol, X., Tobías, A., Pérez, N., Karanasiou, A., Amato, F., Stafoggia, M., Pérez García-Pando, C., Ginoux, P., Forastiere, F., Gumy, S., Mudu, P., Alastuey, A. 2019. Monitoring the impact of desert dust outbreaks for air quality for health studies, Environment International, 130:104867, doi:10.1016/j.envint.2019.05.061.

Serrano-Lomelin, J., Nielsen, C., Jabbar, S., Wine, O., Bellinger, C., Villeneuve, P., Stieb, D,. Aelicks, N., Aziz, K., Buka, I., Chandra, S., Crawford, S., Demers, P., Erickson, A..C, Hystad, P., Kumar, M., Phipps, E., Shah, P.S., Yuan, Y., Zaiane, O., Osornio Vargas, A. 2019. Interdisciplinary-driven hypotheses on spatial associations of mixtures of industrial air pollutants with adverse birth outcomes. Environment International 131: 104972. Doi: 10.1016/j.envint.2019.104972.

World Health Organization. 2020. Air Pollution. https://www.who.int/healthtopics/air-pollution\#tab=tab_1 (accessed May 14, 2020).

Zhai, Y., Li, X., Wang, T., Wang, B., Li, C., Zeng, G. (2018). A review on airborne microorganisms in particulate matters: Composition, characteristics and influence factors. Environment International, 113:74-90, doi:10.1016/j.envint.2018.01.007. 